\title{
AN ANALYSIS OF ORAL COMMUNICATION COMPETENCY OF TENTH GRADE ENGLISH LANGUAGE EXAMINATION IN BALOCHISTAN
}

\section{Qamar Zaman}

Ph.D. Research Scholar,

Department of Education, Khwaja Fareed University of Engineering and Information Technology,

Punjab, Pakistan

Email: bhuttoqamar8@gmail.com

\section{Muhammad Aslam}

Ph.D. Research Scholar,

Department of Education, Khwaja Fareed University of Engineering and Information Technology,

Punjab, Pakistan

Email: aslammalik71@yahoo.com

\section{Madeline Milian}

Professor,

Bilingual / ESL Education, University of Northern Colorado,

Colorado, USA

Email: madeline.milian@unco.edu

\begin{abstract}
It is a natural phenomenon that a language comprises of primarily four skills: reading, writing, listening and speaking. These basic four skills of a language make for effective communication. The English language has a great importance in the Pakistani context because all the competitive examinations are given in English language. In Pakistan, as in many other parts of the world, the English language represents the door of opportunities. However, it has been observed that the teaching of the English language and its assessment at secondary schools in Pakistan has been limited to two skills i.e. reading and writing, whereas, other skills of English language Listening and Speaking which includes linguistic competence, sociolinguistic competence, strategic competence, and discourse competence, are ignored categorically. This study is based on an analysis of Oral Communication Competency through Annual Examination Papers of 2014 to 2019 for Grade Ten in English Language Examination conducted by Balochistan Board of Intermediate and Secondary Education, Quetta in the Province of Balochistan. The study aims to investigate whether activities for learning Oral Communication in the English Text book for grade ten developed by
\end{abstract}


BalochistanTextbook Board, Quetta are included for students of tenth class or not and whether these activities are assessed properly by Balochistan Board of Intermediate and Secondary Education Quetta in annual examination. This research has been carried out in descriptive methods. The research suggests some techniques, rating scale and frame work for measuring oral communication competence. These techniques are helpful in assessing the students' oral communication competence in the province of Balochistan.

\section{KEYWORDS}

English Language Skills, Oral communicative competence, discourse analysis, language proficiency, Rating Scale, Framework

\section{INTRODUCTION}

English enjoys a high status being the widely used international and the official language of Pakistan, (Riaz et al., 2019). The growth of the use of English world in business around the world has transformed the English language into the International Capitalism (Pennycook,1995). In Pakistan, all the Commercial and official transactions, planning, coordination, even letter-writing and day to-day written communication, is often conducted in (Riaz et al., 2019). The use of English is no longer limited to written communication as it was initially happening in the colonial times, but the need of spoken communication is also soaring. Oral communication has a coordinating role in the learning process (Hall, 1993; Wilkinson, 1970). Thus, developing English-Speaking Skill (ESS) and confirming the development of language through a criterion rather than assuming language learners' communicative competence is the need of the day.

It is very natural that a child learns oral skill in language acquisition first and then he/she starts learning reading and writing. There are many people in the World and Pakistan too who can communicate in their daily lives through oral communication and they do not know how to read or write and so is the case with English language. If a person does not know how to make oral communication effectively, definitely he/she will suffer a lot in daily life. Natural language acquisition takes place through understanding messages without understanding each word and structure in it ((Krashen $\&$ Terrell, 1995). There are people in some communities around the world, and in Pakistan, who never make transition to reading and writing (unless necessary). They are satisfied to live in a speaking culture ( (Flowerdew \& Miller).There are tribal languages in South America, Africa and Asia that still have no writing systems (Wei et al., 2019). Teaching speaking skills is one step, learning it in variation is another step but developing and sustaining this skill for real-life application is the top required step which can be aspired through testing. Teaching Oral Communication without testing, and not awarding grades to the students is like denying its importance and 
academic standing. Some teachers find it conducive to grade class discussions and participations to incite the learners to engage in purposeful interaction (Cubillo, n.d.). Henceforth, the education system in Pakistan requires incorporating Oral Communication of English language learning to make the students, linguistically functional and efficient. It is very evident from National Curriculum for English Language 2006 that there are five major strands known as competencies i.e. 1) Reading and thinking skills,2) writing skills, 3) Oral Communication, 4) Grammar and Vocabulary, Ethical and social development for learning English language. According to this national document, the assessment of these learned skills are very necessary whereas, the oral communication competency has been categorically ignored in terms of assessment. In fact, teaching is rounded off by testing, since it is good for teachers and learners to know where they stand (Laar, 1998). Testing is interlinked with improvement (Kanwal, 2016).

Thus, a systematic testing of oral communication may help the learning community as well as the teaching community to observe and plan the constructs of speaking performance to focus their attention to improve. Usually, the oral communication of the students is neither tested systematically nor graded in Pakistan. For testing Oral Communication some modern techniques and tools must be introduced in Annual examinations throughout the country, so that oral communication may be measured accurately. Scientific scaling of oral ability is difficult(Barkaoui et al., 2013). Language teachers must know the purpose of testing language ability to systematically assess the learning ability so that the learners can also conscientiously try to improve in specific areas of measurement. According to Educational Testing System ratings, language learners showcase higher level of proficiency in some aspects of performance than others. The assessment tasks need to be long enough to measure the speaking ability of the assessed. However, it has been observed that there are many activities and much content in the text books of Balochistan Text Books for English Standard 10 regarding enhancement of English Oral Communication, but there is not a single item being tested in Annual Examination conducted by Balochistan Board of Intermediate and Secondary Education Quetta for the period of 2014-2019. This study explores the application of the testing criterion of Oral communication in Annual Examination of Balochistan Board of Intermediate and Secondary Education Quetta.

The researcher initiated study to determine whether oral communication being one of the important competencies of National curriculum of English 2006 is prevalent in Balochistan textbooks of English or it has been categorically neglected. It has been observed that the assessment of Oral Communication skill at tenth class English has not been incorporated by Balochistan Board of Intermediate and Secondary Education Quetta. Teaching without assessment is a futile activity. Teaching becomes aimless when it is not assessed properly. 


\section{LITERATURE REVIEW}

\section{Assessment of oral competency}

According to (Luoma, 2004) assessing any language skill can be a very judgmental issue, in which people tend to relate on native/nonnative speakers on the basis of pronunciation. Additionally, Nunan (1999) viewed that oral competency involves linguistic competence which includes sufficient articulation of sound, clear pronunciation, enough vocabulary and mastery over the syntactical order of a given language with acceptable fluency. Oral competency also needs to relate functional background of language based on psychological background of conversation in a given situation based on logical occurrences. Another competence is strategic competence in which the speaker is able to use strategies of language repairing if discourse is interrupted and halted. And the last one is sociolinguistic / cultural competence. It demands the speakers to use the language appropriately into the context. This theory then developed as the benchmark for assessing Oral Competency. However, the design of Oral Competence assessment may vary; depend on the types of oral skill which is to be assessed. Then, what should to be tested? (Ockey \& Zhi, 2015)

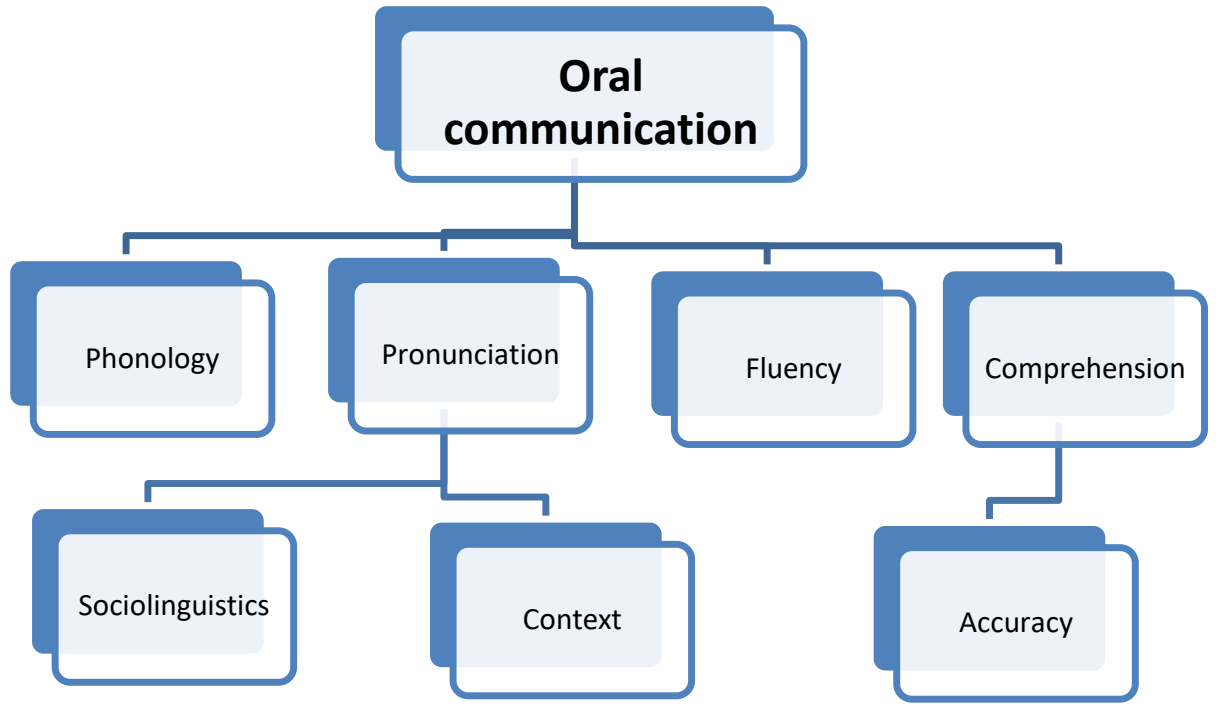

Besides, the knowledge of Grammar, Knowledge of sociolinguistics, knowledge of psycholinguistics and knowledge of pragmatics, Oral communication Skill includes speaking activities such as sharing personal experience, Expressing hopes and fears, expressing refusal politely, exhibit appropriate conventions of interruptions, group discussion, storytelling, exhibit appropriate etiquettes of interacting with audience, picture description, presentation, narrating any event and taking an interview. Without knowing the alignment of above aspects, the language will be merely a bunch of words having no communicative purpose. Bachman and Palmer (2010) said that test takers 
should perform for proficiency of test through a tool measuring language proficiency (Srikaew et al., 2015). Such kinds of tasks will enable students to take initiative in conversation by communicating experiences of real life. These all activities of Oral communication skill need to be assessed in order to determine the learning outcomes of a student. A tool namely rating scale is usually used to measure the performance of a student on Oral Communication Skill. The following aspects of Oral communication may be checked in order to determine the development of oral competency.

\section{Phonology}

The sound system of a given language which works for communication is generally known as phonology. It includes rhyme, alliteration, onset rime, blending, segmenting and phonemic awareness. It is helpful in effective Oral Communication. While assessing Oral communication these are some phonological aspects which must be kept in consideration.

\section{Pronunciation}

Correct Pronunciation is known as a ladder in oral communication. Errors in pronunciation become cause for poor communication which leads to communication gap. This aspect of language is important in assessment perspective.

\section{Fluency}

The Oral communication fluency in a language indicates that the production of speech is smooth that is well delivered with confidence having an aim of purposeful communication. It's a measureable item of a language. Teaching of this part of Oral communication without measuring and assessing learning outcomes is tantamount to beating about the bush.

\section{Grammar}

Grammar is very useful in Oral communication skill for sequencing the spoken chunks and putting them properly in syntactical order for structuring and constructing accurate meaningful sentence patterns for various purposes in a discourse.

\section{Vocabulary}

The Level of test takers can be assessed by the usage of lexical items used in conversation. Vocabulary is known as a Skelton of a language which gives shape to a conversation. The more vocabulary a person has, the more fluent a person will be.

\section{Comprehension}

When a person understands the given conversation, while responding to any question in a speech with full understanding of context and nature of speech is said to be capable of overcoming comprehension problem. 


\section{Task}

Task is a kind of an assignment given to test takers during the assessment of Oral Communication skill. This assessment should be fair, valid and clear for achieving its intending purposes. There are different factors which may affect the validity of assessment of Oral Communication skill. Therefore, it should be conducted in objectivity without any influence of external factors.(Hughes, 2003; Luoma, 2004; Nunan, 1999):

While taking a test, the test giver must look into the external influences which may affect the performance of test taker. Different external factors like environment of room, noise, time of test, test takers' mood and motivation, setting of place and many other factors may influence the performance of test taker of Oral Communication skill. Therefore, when a test giver is developing any test on Oral Communication skill, the above mentioned influences must be considered.

\section{Formation of tasks in assessing oral communication skills}

There are many popular tasks for assessing oral communication skill. (El et al., n.d.) described some important types for assessing oral communication skill which were known as "oral production tests" that were used in the 1960s, namely: Scored interviews, Paired and group discussion, Simulated Tasks, Integrated oral communication tasks, Elicited imitation tasks, Highly structured speech samples, and paper-and-pencil tests. In the first type of test, the trained assessors engage a student in conversation and measure their ability on a designed rating scale. Interviews have very important place in assessing the Oral communication skill. The format of interview is rampant for every job in Pakistan for assessing one of the abilities of aspirants' which is oral communication skill. Through an interview the assessor peeps into the personality of test taker for particular intended objective. In Paired and group discussion type of task some oral activities are assigned to pair or in groups so as to become fluent in oral communication skill. In the Elicited imitation type of task depends on preset objectives and it has not involvement of any speaker. The examples for this kind of task are repetition of sentence and reading a passage aloud through automated machines. (El et al., n.d.) described that in the paper-and-pencil tests task the written responses were required for finding out different items of language which may include identifying word stress, rising tone, ellipse, finding rhyming words. This format of test was known as paper and pencil tests for oral communication skill. This pattern of assessing oral communication skill has been decreased due to dominancy of mechanical brains.

We now discuss five popular types of task used to assess oral communication. These types of tasks are helpful in assessing Oral communication proficiency. These tasks are 1) Oral proficiency interviews, 2) Paired/group oral discussion tasks, 3) Simulated 
tasks, 4) Integrated oral communication tasks, 5) Elicited imitation tasks. The first three task types are variants of scored interviews, while the last two are variants of the highly structured samples.

\section{Interviews for Oral Proficiency}

Interviews are commonly used for assessing the Oral Proficiency of students. In this type of task format, the students are supposed to respond the questions raised by the interviewer on the selected topic. The responses are noted in a tool designed for this purpose. The interviewer is raising cross questions in order to elicit the language stuff from the interviewee.

The American Council on the Teaching of Foreign Languages (ACTFL) is an example of task format for Oral Proficiency. A tool for assessing oral communication namely "standardized procedure for the global assessment of functional speaking ability", was developed in the 1980s and still it is widely used in a number of foreign languages for assessing the proficiency in Oral communication (ACTFL 2012; Liskin-Gasparro 2003). In this tool (ACTFL OPI) the interview is asking many personal questions from the interviewee on telephone. In this type of test the interviewer indulges the test taker into different types of questions ranging from personal to general and common to abstract. This ACTFL OPI format of test mainly goes through with four important phases which are warm up, level checks, Review and wind-blown. The Warm up step starts with simple general questions and rapport building for elimination of interview fear from the test taker. At the level check step, the interviewer asks different question to establish proficiency level of test taker and can measure to what extent the test taker is proficient in Oral communication. At the probe step the interviewer is asking deep questions which are beyond the expectation of test taker to see whether the test taker has a superficial command over the oral skill or he/she can materialize the abstract ideas into the form of oral communication. In this pattern of assessing oral communication two modern technologies are used namely ACTFL-telephonic and the internet version. In the telephonic test the interviewer calls the test taker on phone rather than face to face interview and assesses proficiency of test taker. Through this kind of interview the test taker will assess a number of aspects involved in oral communication including grammatical accuracy, semantically order, fluency, usage of vocabulary and understanding of pragmatics in real life situation. However, it is very obvious that the discourse in natural setting is different from this structured conversation. (Hurst et al., n.d.) It is reality that in this format of assessing of language skills the interviewer is naturally dominant and the test taker may be affected by the mood, behaviour and subjectivity of interviewer which influences adversely on the achievement of performer. For example one interviewer is less friendly than other interviewer that is unequal power between the test taker and test giver (MacDonald et al., 2001). 


\section{Paired and group oral discussions}

Paired and group discussion can improve oral communication. In this format, the students are distributed into pairs or small groups and they have been asked to initiate discourse on the given theme. The teacher will work as a facilitator for helping the students, if they face any difficulty. While pairing the students, the status of test takers must be rationalized based on different criteria, for example rapport of pair, proficiency level and interaction. Another example of the task is group discussion. In this task more than two test takers are involved in a conversation on the given topic for assessing the oral communication skill. This task is carried out in the class room with the help of test giver. This group discussion task may also be initiated on computer as TOEFL iBT test. Computer based discussion task can be initiated in the college English test for the group discussion (He and Dai 2006). The importance of group oral tasks in assessing oral communication was acknowledged in the year of 1980s and its importance has been growing with precedent of implementation of this type of tasks in Cambridge Main Suite Examinations in the UK and Cambridge Certificate in Advanced English (CAE). The Agha Khan Board of Intermediate and Secondary Education Karachi is also using this format of task in order to assess the competence of test takers' oral communication skill. Pair or group discussion task are used at Michigan State University in the USA for placement of test taker (Winke 2013). In the era of modern technology group discussion can be facilitated through inter-net/computer based video-conference, Adobe Connect, and Skype. Information Communication Technology has brought eases and comfort in assessing oral communication skill. By using ICT, the synchronous voice based computer mediated communication (CMC), the performance of test taker can be assessed easily (Alastuey 2011; Lin 2014).The performance of test takers must be assessed on a rating scale which comprises of different oral communication items such as Grammar, Pronunciation, Vocabulary, Stress patterns, Intonation and fluency (Zhenge\& Cheng, 2008). The group and oral tasks are instrumental in assessing the interactional competence of test takers at Oral communication skills because the task provides opportunities to collaborate with each other for eliciting the measurable oral competence.

\section{Simulated tasks}

For assessment of oral communication of English simulated tasks are commonly used. Simulation tasks include role plays and performance of real life situations in the class room. In this task the test takers are given a particular role which he/she has to play in a simulated task, for example a meeting with doctor to tell him about decaying health. Moreover, the test takers select the task from the given choices and perform it in the presence of assessor. Apart from this pattern of paper based task there is another way of assessing oral communication skill through computerize discourse completion tasks (DCT) with a video based prompt (Sydorenko, Maynard \& Guntly 2014). In this task a video prompt is displayed before the test takers in which different situations are 
created for test takers responses. The computer is creating different prompts orally and the test taker has to respond computer technology. There will be conversation with turn taking. Sydorenko, Maynard \& Guntly (2014) suggested that the computer based simulation is better than the paper based discourse completion tasks for assessing oral communication skill of test taker. The example of simulation in our context is banking system. If someone has to activate ATM card, he/she has to contact on help line where there are computer based instructions. By following those computer based instructions and responding queries, one can achieve success. In this prompt the competency of test takers' could be elicited and assessed through technology based communication.

\section{Integrated tasks}

Integrated tasks are those tasks which aim to measure more than one sill or sub skills at a time. The test takers have been asked to listen to some instructions and respond it accordingly then write the results which come at the end. There is no one way speech like monologue oral presentation without any questions or answers. The tasks involve mainly speaking and listening that's why we would say that integrated task format is useful in assessing oral communication skill. Integrated tasks are very much rampant in many English language assessment tests like TOEFL iBT and IELTS. In an integrated system of language assessment, here are some listening techniques in which a test taker has to listen to the given discourse and then give responses based on listening. The speaker in that given discourse may have different characters depicting different situations. There is no need of interlocutor during this task performing, because this integrated task is primarily computerized based, assessing the integrated tasks, such as the listening-reading-speaking which aim at rating of phonology, fluency, grammar and vocabulary. The different strategies can be used for assessing the integrated tasks in oral communication (Barkaoui, Brooks, Swain, and Lapkin 2012).The test taker's strategy used in integrated tasks may also be different from other task types (CampoyCubillo\& Edo Marza, 2015)

\section{Elicited imitations}

In this kind of task, the test taker listen to the particular item of language and repeats it as closely as he/she could. The standard of test is assessed on the basis of standard of test taker. This task may include imitation of a word, phrase, or a sentence to determine the pronunciation and fluency of test taker. Even though in today's modern era this format of assessment in oral communication is diminishing but still we can see the remnants in language testing. This task type is assessed by using automated speech recognition (ASR) technology scoring which extracts different language items from test takers' speech samples (Bernstein 2013). This format for assessing oral communication is helpful at early grades, whereas; human interaction is more complex than imitation of merely one or two sentences. However, it can be denied that this format is helpful in language assessment in general and oral communication in 
particular.

Strategies for testing oral competency

The following strategies were used to test the oral productive skills:

- Oral Productive Skills (Recorded on Video)

- Monologue

- Questions and answers;

- Dialogues and interviews

- Role-play based on a learned dialogue;

- Description of pictures;

\section{Rating Scale for testing oral competency}

- Feeling hesitation in speaking

- Speaks in complete sentences

- Well-structured sentences

- Adequate range of voc. and structures

- Speaks only in target language

- Speaks without reliance on written text

- Speaks with clarity which is understandable.

- Pronounces words competently

- Having a little influence of Native language.

- Speech is expressive and appropriately intonated

- Flow of speech is rhythmic and continuous

- Is aware of pers. and interpersonal space

- Displays effective use of body language

- Displays effective use of facial expression

- Displays confidence in the interactive process

RATING SCHEDULE FOR SCORING

"COMMUNICATIVE COMPETENCE"

Topic Code: Assessor(s):

Student's Name:

Date:

Role-Play

$\mathrm{ACC}=$ Accuracy; FLU = Fluency;

RNG $=$ Range 1 = Never; 2 = Infrequently; 3 = Frequently, $4=$ Mostly; $5=$ Always Fluency

\begin{tabular}{llllll}
\hline a) Responds with little hesitation & 1 & 2 & 3 & 4 & 5 \\
b) Speaks in complete sentences. & 1 & 2 & 3 & 4 & 5 \\
c) Sentences are well structured & 1 & 2 & 3 & 4 & 5 \\
d) Uses adequate range of voc. and structures & 1 & 2 & 3 & 4 & 5 \\
\hline
\end{tabular}




\begin{tabular}{llllll}
\hline e) Speaks without reliance on written text & 1 & 2 & 3 & 4 & 5 \\
$\begin{array}{l}\text { f) Speech is clear and comprehensible } \\
\text { g) Flow of speech is rhythmic and continuous }\end{array}$ & 1 & 2 & 3 & 4 & 5 \\
$\begin{array}{l}\text { Accuracy } \\
\text { e) Speaks only in English }\end{array}$ & 2 & 3 & 4 & 5 \\
h) Pronounces words competently & 1 & 2 & 3 & 4 & 5 \\
$\begin{array}{l}\text { i) Speaks with little influence of Mother Tongue 1 } \\
\text { j) Speech is expressive and appropriately intonated1 }\end{array}$ & 2 & 2 & 3 & 4 & 5 \\
1) Is aware of pers. and interpersonal space r 1 & 2 & 3 & 4 & 5 \\
m) Displays effective use of body language & 1 & 2 & 3 & 4 & 5 \\
n) Displays effective use of facial expression & 1 & 2 & 3 & 4 & 5 \\
o) Displays confidence in the interactive process 1 1 & 2 & 3 & 4 & 5 \\
\hline
\end{tabular}

\section{RESEARCH OBJECTIVES}

1. To find out questions having focus on Oral Communication Skills in the Annual Examination Conducted by BISE Quetta.

2. To determine techniques for assessing Oral Communication Skills.

\section{RESEARCH QUESTIONS}

1. What is oral communication skill?

2. How Oral Communication skills can be assessed?

3. Which techniques are helpful in assessing the Oral Communication Skills?

\section{RESEARCH METHODOLOGY}

In this research, mixed approach was followed. Documents review comprised of National Curriculum of English 2006, Balochistan Text Book Board Quetta and Question Papers and syllabus for the subject of English Class ten of Balochistan Board of Intermediate and Secondary Education Quetta have been used for data collection. Balochistan is the largest province in area, spread over $43 \%$ of the total area of Pakistan. There is only one Board for conducting examination of SSC and HSC. The name of this Board is Balochistan Board of Intermediate and Secondary Education Quetta. According to the statics given by Balochistan BISE, the number of students who have appeared in SSC Examination in the year 2020 is 120,000 which are increasing $10 \%$ every year. The question papers were reviewed from the year 2014 to 2019 in order to ascertain that how many activities of oral communication skills are included which are given in English Text book of tenth class developed by Balochistan Text Book Board Quetta. Concerning the assessment of oral competency in the subject of English which is compulsory at SSC level, the tools like rating scale and tasks based rubric on communication were developed. These tools were piloted by two raters while keeping the question papers from the year 2014 to 2019 in mind. In order to ensure reliability between the raters, the developed tools were given separately to raters for 
filling. The filled tools were compared the similarities and differences between their scores and discussed the marked questions in the rubric.

\section{FINDINGS}

The researcher has observed that there are nineteen activities for enhancement of Oral Communication in Balochistan Textbook Board, Quetta for the tenth class English subject. These nineteen activities are covered under the Different oral activities like Express hopes and fears (English, p.17), Express Refusal politely (English, p. 36), Exhibit appropriate conventions of interruptions (English, p.58), Create and deliver simple group/class presentation (English, p.82), Group Discussion (English, p.91), share information and ideas (English, p.105), exhibit appropriate etiquettes of interacting with audience (English, p.121), Ask, restate and simplify directions and instructions through Oral techniques (English, p. 133). The mode of conducting oral communication includes Role play, Discussion, Interviews, presentations, sharing information etc, which are instrumental in augmentation of oral communication skill of student of tenth class. The harrowing fact is that there is not a single activity included in Balochistan Board of Intermediate and Secondary Education Quetta Annual Examination Papers for the year 2014 to 2019 for the assessment of Oral Communication English Skill for the students of tenth class. Such a way the assessment of oral communication of students has been ignored and it has not been measured properly. Consequently, the purpose of curriculum (NCE-2006) can't be achieved which shows a big gap between the curriculum and the assessment of students on Oral communication skill which is the $2^{\text {nd }}$ competency of National Curriculum of English 2006.

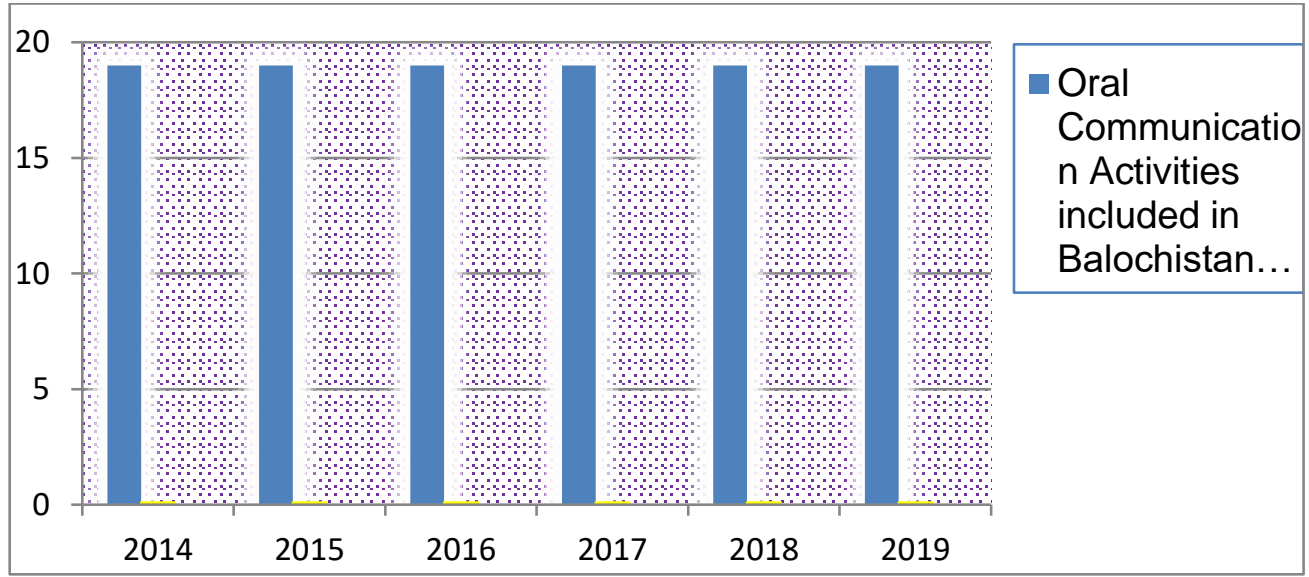

Table. 1: 


\section{CONCLUSION}

Though it is a complex process to assess Oral communication but it is not an impossible task to achieve. It requires adroit endeavor and techniques to accomplish assessment of oral communication. There are many factors which affect oral communication. Oral Communication has vitality in acquisition of language in real context. The researcher has suggested that the major different aspects of oral communication should be assessed which frames the oral communication. These aspects include Interactional competence, grammar, vocabulary, phonology and fluency. Testing tasks and rubric should be utilized in the examination for assessment of oral communication skill for assessing these four key aspects of oral communication a judicious rubric should be used in examination for determining the Oral competency of students. Besides the rubric, different types of tasks should be given in various contexts while looking the purpose of assessment. Even though teaching of oral communication skill of English is taking place in all secondary schools of Balochistan province but there are not any adequate measures to assess oral communication skill.

In addition, it is recommended that Balochistan Board of Intermediate and Secondary Education Quetta should incorporate some questions for assessing Oral Communication in its Annual Examinations of tenth class for the subject of English. In such a way there will be an alignment ranging from National Curriculum to Balochistan Textbooks and Balochistan Board of Intermediate and Secondary Education Quetta. This alignment will be instrumental in achieving the aims of Curriculum at national level.

\section{RECOMMENDATIONS}

This study will provide an opportunity to Examination conducting Boards for inclusion of Oral Communication Competency in all the Question papers of English subject in every standard. There is a big portion of Student Learning Outcomes (SLOs) included in National Curriculum of English and Balochistan Text book board for the subject of English in every class but their Oral Communication skill is not measured properly at any level. This will affect adversely because one of the major portions of language has been categorically ignored, consequently a child will not get competence in English Language. It is inevitable to measure the Oracy skill at all level in the country. If one part is left behind, no language competence will be achieved by student. All the Boards of Intermediate and Secondary Education of the country generally while Board of Intermediate and Secondary Education Balochistan particularly should emphasize on the measurement of Oral communication skill. If this skill is ignored at this stage then this will be learning barrier for a student to rest of his life. World is changing rapidly and there are globally connections through internet, social media and Mobiles. These changes have created situation that have increased the importance of Oral communication in the lives of most students and citizens. If a student has no 
competence in Oral Communication Skill, he will be disconnected from the globally developmental phase. In order to evade from these all perils, Assessment of Oral Communication must be ensured to meet the challenges of dynamic world.

However, it is recommended that all the language activities given in text book must be assessed in annual examination. If these activities are not assessed then there is no use of including Oral communication skill activities in the English textbooks of Balochistan province. Board of Intermediate and Secondary Education may seek help from Agha Khan Board Karachi or some other boards which are assessing students on Oral Communication Skill. Besides, Balochistan provincial Government must introduce continuous professional development programes for English teachers so that they can teach language in a very efficient way to benefit students of province.

\section{REFERENCE}

Bachman, Lyle. (2013). Ongoing Challenges in Language Assessment. 10.1002/9781118411360.wbcla128.

Barkaoui, K., Brooks, L., Swain, M., \& Lapkin, S. (2013). Test-takers'strategic behaviors in independent and integrated speaking tasks. Applied Linguistics, 34(3), 304-324. https://doi.org/10.1093/applin/ams046

Cubillo, P. C. (n.d.). A Sample Lesson Plan For The Course English Composition Ii Of The Reading And Writing Skills/Lesson Planning/Suggestions For Further Research In The Field Of Writing In Efl.

El, S. A., Torky, F., Abd, A., \& Maksoud Zaher, E. (n.d.). The Effectiveness of a Task-Based Instruction program in Developing the English Language Speaking Skills of Secondary Stage Students Supervised by Curricula and Methods of teaching Department.

Hurst, B., Wallace, R., \& Nixon, S. B. (n.d.). Reading Horizons: A Journal of Literacy and Reading Horizons: A Journal of Literacy and Language Arts Language Arts The Impact of Social Interaction on Student Learning The Impact of Social Interaction on Student Learning. https://scholarworks.wmich.edu/reading_horizons

MacDonald, M., Badger, R., \& White, G. (2001). Changing values: What use are theories of language learning and teaching? Teaching and Teacher Education, 17(8), 949-963. https://doi.org/10.1016/S0742-051X(01)00042-7

Ockey, G. J., \& Zhi, L. (2015). New and not so new methods for assessing oral communication. Language Value, 7, 1-21. https://doi.org/10.6035/languagev.2015.7.2

Riaz, N., Haidar, S., \& Hassan, R. (2019). Developing English Speaking Skills: Enforcing Testing Criteria. Global Social Sciences Review, IV(II), 132-142. https://doi.org/10.31703/gssr.2019(iv-ii).18

Wei, Y., Li, Y., Xu, M., \& Huang, W. (2019). A review of early fault diagnosis approaches and their applications in rotating machinery. In Entropy (Vol. 21, Issue 4). MDPI AG. https://doi.org/10.3390/e21040409 